\title{
Produção de coentro cultivado com esterco bovino e adubação mineral
}

\author{
Ademar P. Oliveira ${ }^{1}$; Virna Raquel F. Silva ${ }^{2}$; Claudiomir S. Santos ${ }^{2}$; Jucilene S. Araújoº ${ }^{2}$ João T. Nasci- \\ mento ${ }^{2}$ \\ ${ }^{1}$ UFPB - CCA, C. Postal 02, 58.397-000 Areia-PB, bolsista CNPq, E-mail: ademar@cca.ufpb.br. ${ }^{2}$ Alunos de Pós-Graduação em \\ Agronomia, CCA-UFPB.
}

\section{RESUMO}

Avaliou-se o efeito de doses de esterco bovino na presença e ausência de adubo mineral sobre o rendimento do coentro, cv. Verdão. O experimento foi conduzido na UFPB, entre março e maio/2001, no delineamento de blocos casualizados, com os tratamentos distribuídos em esquema fatorial $5 \times 2$, correspondendo às doses de esterco bovino $\left(0 ; 2,0 ; 4,0 ; 6,0\right.$ e $\left.8,0 \mathrm{~kg} / \mathrm{m}^{2}\right)$ e, presença e ausência de adubo mineral $\left(10 \mathrm{~g} / \mathrm{m}^{2}\right.$ de $\mathrm{P}_{2} \mathrm{O}_{5}, 6,0 \mathrm{~g} / \mathrm{m}^{2} \mathrm{~K}_{2} \mathrm{O}$ e $50 \mathrm{~g} / \mathrm{m}^{2}$ de $\left.\mathrm{N}\right)$, em quatro repetições. A altura das plantas aumentou com a elevação das doses de esterco bovino apenas quando na presença de adubação mineral, ocorrendo incremento na ordem de 0,42 e $1,47 \mathrm{~cm}$ na altura, aos 20 e 40 dias, respectivamente, a cada quilograma de esterco bovino adicionado ao solo. A dose de $3,8 \mathrm{~kg} / \mathrm{m}^{2}$ de esterco bovino, na presença do adubo mineral, proporcionou número máximo de molhos $(49,0)$, enquanto que na ausência de adubo mineral o número de molhos, aumentou com a elevação das doses de esterco bovino, na ordem de 3,0 molhos para cada quilograma de esterco bovino adicionado ao solo. O rendimento máximo estimado de massa verde $\left(5,0 \mathrm{~kg} / \mathrm{m}^{2}\right)$ foi obtido com $3,9 \mathrm{~kg} / \mathrm{m}^{2}$ de esterco bovino na presença do adubo mineral, enquanto que na ausência de adubo mineral o rendimento de coentro, aumentou com a elevação das doses de esterco bovino, na ordem de $0,24 \mathrm{~kg} / \mathrm{m}^{2}$ a cada quilograma de esterco bovino adicionada ao solo.

\begin{abstract}
Yield of coriander cultivated with cattle manure and mineral fertilization

The effect of different levels of cattle manure was evaluated in the presence and absence of mineral fertilizer on coriander, cv. Verdão production. The experimental plots were placed at Universidade Federal da Paraíba, in Areia, Brazil, from March to May 2001. The experiment was set up in a randomized block design, with treatments distributed in a 5 x 2 factorial scheme, corresponding to levels of cattle manure ( 0 ; $2.0 ; 4.0 ; 6.0$ and $8.0 \mathrm{~kg} \mathrm{~m}^{-2}$ ) and presence or absence of mineral fertilization $\left(10 \mathrm{~g} / \mathrm{m}^{2}\right.$ of $\mathrm{P}_{2} \mathrm{O}_{5}, 6.0 \mathrm{~g} / \mathrm{m}^{2}$ of $\mathrm{K}_{2} \mathrm{O}$ and $\left.50 \mathrm{~g} / \mathrm{m}^{2} \mathrm{~N}\right)$, with four replications. There was an increase of 0.42 and $1.5 \mathrm{~cm}$ in plant height, for 20 and 40 days, respectively, for each kilogram of cattle manure applied to soil. In the presence of mineral fertilizer, a cattle manure level of $3.8 \mathrm{~kg} \mathrm{~m}^{-2}$ provided the highest number of bunches (49.0), while in the absence of mineral fertilizer the number of bunches of coriander increased with the increasing levels of cattle manure. This increase was in the order of 3.0 bunches for each kilogram of cattle manure added to soil. An estimated maximum yield of green mass $\left(5.0 \mathrm{~kg} \mathrm{~m}^{-2}\right)$ was obtained with $3.9 \mathrm{~kg} \mathrm{~m}^{-2}$ of cattle manure in the presence of mineral fertilization, while in the absence of mineral fertilizer coriander yield increased with higher levels of cattle manure, in the order of $0.24 \mathrm{~kg} \mathrm{~m}^{-}$ ${ }^{2}$ for each kilogram of cattle manure added to the soil.
\end{abstract}

Keywords: Coriandrum sativum L., organic-mineral fertilization, yield.
Palavras-chave: Coriandrum sativum L., adubação organo-mineral, produção.

(Recebido para publicação em 29 de março de 2000 e aceito em 25 de março de 2002)

$\mathrm{O}$ coentro (Coriandrum sativum L.) é uma olerícola, consumido em diversas regiões do Brasil, especialmente no Norte e Nordeste. Seu cultivo visa não somente a obtenção de massa verde utilizada na composição de diversos pratos, como o uso para tempero. As sementes são bastante utilizadas na indústria como condimento para carne defumada e na fabricação de pães, doces, picles e licores finos. (Pedrosa et al., 1984). Na Paraíba, é cultivado em quase todas as micro-regiões por pequenos produtores sem nenhuma orientação, o que tem ocasionado queda no rendimento, principalmente devido à falta de um programa de nutrição mineral.

É possível a produção de coentro empregando-se unicamente adubo orgânico. Entanto, a aplicação de adubos minerais favorece o desenvolvimento vegetativo das plantas e o volume de folhas produzi- das (Filgueira, 1987). A aplicação de nitrogênio nos primeiros 20 dias após a semeadura, garante um rápido crescimento vegetativo. Tomar et al. (1994) obtiveram aumento significativo na produção de folhas por planta com altas doses de $\mathrm{N}(80$ $\mathrm{kg} / \mathrm{ha}$ ), de $\mathrm{P}_{2} \mathrm{O}_{5}$ (40 kg/ha) e de $\mathrm{K}_{2} \mathrm{O}$ (30 $\mathrm{kg} / \mathrm{ha}$ ). Singh \& Rao (1994) obtiveram ótimos rendimentos com $93 \mathrm{~kg} / \mathrm{ha}$ de nitrogênio, enquanto Sharma \& Israel (1991) não verificaram alterações significativas no rendimento do coentro em resposta às aplicação de fósforo, porém, com a utilização de $120 \mathrm{~kg} \mathrm{~N} / \mathrm{ha}$, ocorreu elevação na produção de massa verde.

É reconhecida a importância e a necessidade da adubação orgânica em hortaliças, principalmente nas folhosas visando compensar as perdas de nutrientes ocorridas durante seu cultivo (Kimoto, 1993). Em repolho, (Silva Júnior, 1984), bem como na alface, (Vidigal et al., 1997) houve aumento na produção dessas horta- liças quando foram adubadas apenas com esterco bovino.

Pouco se sabe sobre a quantidade de esterco bovino a ser adicionada ao solo, visando aumento no rendimento de massa verde, melhoria das condições físicas do solo e utilização eficiente dos nutrientes pelo coentro. Filgueira (2000) relata que a aplicação de esterco bovino e de galinha favorecem o crescimento do coentro. Pedrosa et al. (1984) para as condições do Nordeste, recomendam a utilização de 20 t/ha de esterco de curral, a lanço ou incorporadas ao solo, enquanto Pimentel (1985) para as condições da região Norte, recomenda o emprego de 50 t/ha de esterco bovino ou $20 \mathrm{t} /$ ha de esterco de galinha. Deste modo, o presente experimento teve como objetivo avaliar o efeito da aplicação do esterco bovino, na presença e ausência de adubo mineral, sobre o rendimento de coentro. 


\section{MATERIAL E MÉTODOS}

O experimento foi instalado na UFPB, em Areia, de março a maio de 2001, em Latossolo Vermelho-Amarelo. Foram estabelecidos dez tratamentos, constituídos de cinco doses de esterco bovino na presença e ausência de adubo mineral, distribuídos em esquema fatorial $5 \times 2$ em blocos casualizados com quatro repetições. A análise do solo indicou a seguinte composição: $\mathrm{pH}=$ 6,$0 ; \mathrm{P}=51,21 \mathrm{mg} / \mathrm{dm}^{3} ; \mathrm{K}=133,0 \mathrm{mg} /$ $\mathrm{dm}^{3} ; \mathrm{Al}^{+3}=0,0 \mathrm{cmol} / \mathrm{dm}^{3} ; \mathrm{Ca}^{+2}=4,20$ $\mathrm{cmol} / \mathrm{dm}^{3} ; \mathrm{Mg}^{+2}=0,30 \mathrm{cmol} / \mathrm{dm}^{3}$ e matéria orgânica $=19,71 \mathrm{~g} / \mathrm{dm}^{3}$. O esterco bovino apresentou as características: $\mathrm{P}$ $=3,6$ g. $\mathrm{kg}^{-1} ; \mathrm{K}=4,1 \mathrm{~g} \cdot \mathrm{kg}^{-1} ; \mathrm{N}=3,8$ g.kg1; matéria orgânica $=182,07$ g.dm ${ }^{-3}$; e relação $\mathrm{C} / \mathrm{N}=10 / 1$.

As doses de esterco bovino $(0,0 ; 2,0$; 4,$0 ; 6,0 ;$ e $8,0 \mathrm{~kg} / \mathrm{m}^{2}$ ), foram aplicadas juntamente com o adubo mineral, sete dias antes da semeadura. A adubação mineral consistiu da aplicação de $10 \mathrm{~g} /$ $\mathrm{m}^{2}$ de $\mathrm{P}_{2} \mathrm{O}_{5}$ e de $6,0 \mathrm{~g} / \mathrm{m}^{2}$ de $\mathrm{K}_{2} \mathrm{O}$, no plantio e de $10 \mathrm{~g} / \mathrm{m}^{2} \mathrm{de} \mathrm{N}$, aplicado em adubação de cobertura, parcelando 50\% aos 20 e $50 \%$ aos 40 dias após a semeadura (DAS).

O preparo do solo constou da construção de leirões e abertura de sulcos de plantio. As parcelas mediram 2,0 $\mathrm{m}^{2}$. As sementes de coentro (cv. Verdão) foram distribuídas em sulcos longitudinais espaçados de $0,30 \mathrm{~m}$, a uma profundidade de 3,0 cm, realizando-se o desbaste quinze dias depois, deixando-se uma planta a cada $5,0 \mathrm{~cm}$.

Realizaram-se os tratos culturais normais para a cultura, incluindo irrigação por aspersão, procurando-se fornecer quantidade de água suficiente para o bom desenvolvimento da cultura, além de capinas manuais, procurando-se manter a cultura livre de plantas invasoras. Dispensou-se o emprego de defensivos agrícolas, devido à ausência de pragas e doenças.

Foram obtidos dados de altura de plantas aos 20 e 40 DAS, número de molhos $/ \mathrm{m}^{2}$ (compostos de caule e folhas), e a produção de massa verde. Foi considerado um molho, aquele com 100 $\mathrm{g}$ de plantas e a produção de massa verde, ao peso do talo e folhas verdes.

Os resultados obtidos foram interpretados por meio das análises de variância e de regressão, utilizando-se o "software"

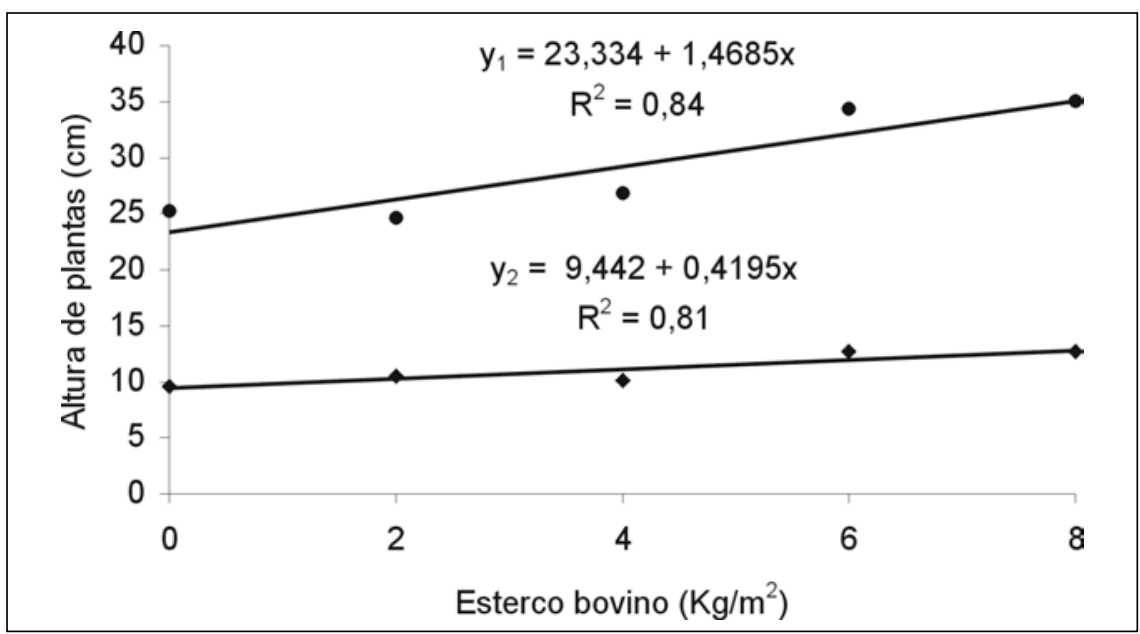

Figura 1. Altura de plantas de coentro cultivar Verdão aos $20\left(\mathrm{Y}_{2}\right)$ e $40\left(\mathrm{Y}_{1}\right)$ dias, em função de doses de esterco bovino na presença de adubação mineral. Areia, UFPB, 2001.

SAEG (2000). Quando possível, os modelos de regressão linear e quadrática foram utilizados para estimar as respostas das características avaliadas. Nas significâncias das análises de variância e de regressão foram considerados os níveis de probabilidade de $5 \%$ e $1 \%$ pelo teste F. O teste " $t$ " foi utilizado para obter os coeficientes da regressão nos níveis de probabilidade de $5 \%$ e $1 \%$.

\section{RESULTADOS E DISCUSSÃO}

A altura das plantas e o rendimento de molhos e de massa verde do coentro foram influenciados $(\mathrm{P}=0,05)$ pelos tratamentos. A altura das plantas aumentou com a elevação das doses de esterco bovino, apenas na presença de adubação mineral, ocorrendo incremento na ordem de 0,42 e $1,5 \mathrm{~cm}$ na altura, aos 20 e 40 dias, respectivamente, a cada quilograma de esterco bovino adicionado ao solo (Figura 1).

Pela derivação da equação de regressão, calculou-se a dose de $3,8 \mathrm{~kg} / \mathrm{m}^{2}$ de esterco bovino na presença do adubo mineral, como aquela responsável pelo número máximo estimado de molhos $(49,0)$, enquanto que na ausência de adubo mineral, o número de molhos aumentou em 3,0 molhos a cada quilograma de esterco bovino adicionado ao solo (Figura 2).

Pela curva ajustada a partir da equação polinomial (Figura 3), verificou-se que a produção de massa verde na presença de adubo mineral atingiu valor máximo estimado $\left(5,0 \mathrm{~kg} / \mathrm{m}^{2}\right)$ na dose ótima estimada de $3,9 \mathrm{~kg} / \mathrm{m}^{2}$ de esterco bovino. Na ausência de adubo mineral, a produção de massa verde aumentou com a elevação das doses de esterco bovino, proporcionando incremento de $0,24 \mathrm{~kg} / \mathrm{m}^{2}$ a cada quilograma de esterco bovino adicionada ao solo (Figura 3 ).

A produção máxima estimada de massa verde $\left(5,0 \mathrm{~kg} / \mathrm{m}^{2}\right)$ obtida pelo uso do esterco bovino, na presença do adubo mineral, considerada alta, evidencia uma boa produtividade de coentro, cultivar Verdão na micro-região de Areia e supera o rendimento médio do estado de Pernambuco, em torno de $4,0 \mathrm{~kg} / \mathrm{m}^{2}$ em cultivos convencionais (Hortivale, 1987) e o rendimento médio da região Norte em torno de 3,5 kg/m² (Pimentel, 1985).

Há consenso entre diversos autores sobre a eficiência do esterco bovino associado ou não a adubos minerais em elevar a produção de hortaliças. Em feijão-vagem (Santos et al., 2001) e em repolho (Oliveira et al., 2001), houve aumento na produção dessas hortaliças quando foram adubados apenas com esterco bovino. Associando esterco bovino a adubos minerais, Oliveira et al. (2001a) em inhame e Oliveira et al. (2001b) em feijão-caupi, observaram que na presença da adubação mineral a elevação no rendimento dessas hortaliças se deu com doses de esterco bovino, inferiores àquelas responsáveis pelas máximas produções na sua ausência.

$\mathrm{O}$ número máximo de molhos e o rendimento máximo de massa verde do coentro, respectivamente, obtidos com 3,8 e $3,9 \mathrm{~kg} / \mathrm{m}^{2}$ de esterco bovino e adubos minerais, inferiores à dose mais ele$\operatorname{vada}\left(8,0 \mathrm{~kg} / \mathrm{m}^{2}\right)$, pode indicar que quando são fornecidos adubos minerais de forma equilibrada, não se faz necessária a utilização de esterco bovino em 


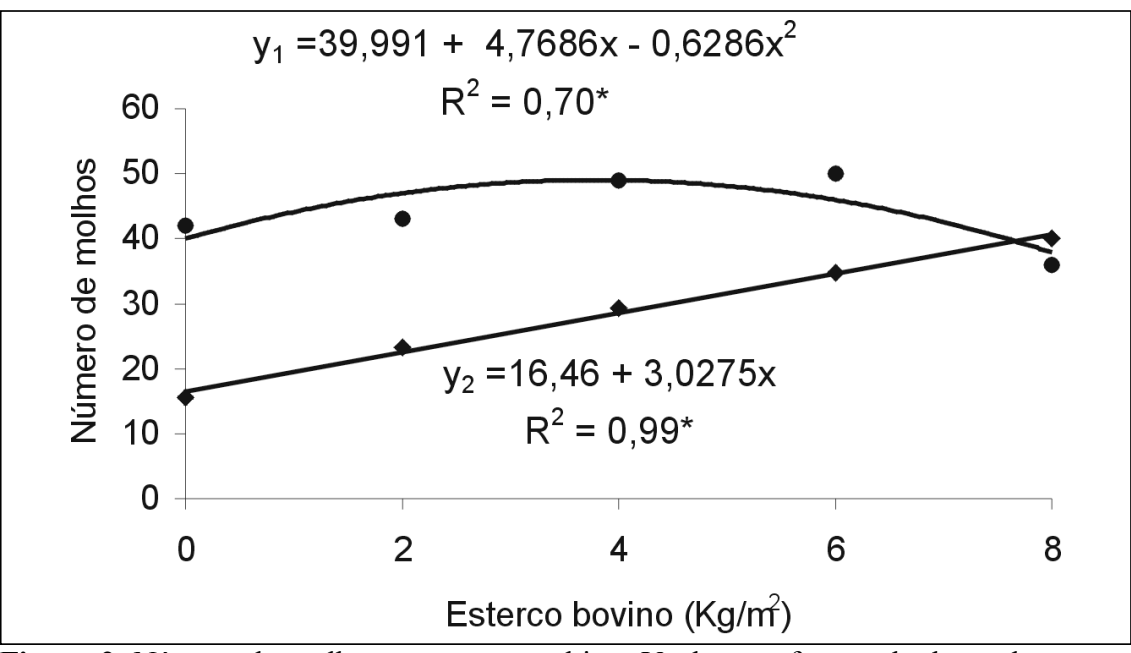

Figura 2. Número de molhos no coentro cultivar Verdão em função de doses de esterco bovino na presença $\left(\mathrm{Y}_{1}\right)$ e ausência $\left(\mathrm{Y}_{2}\right)$ de adubo mineral. Areia, UFPB, 2001.

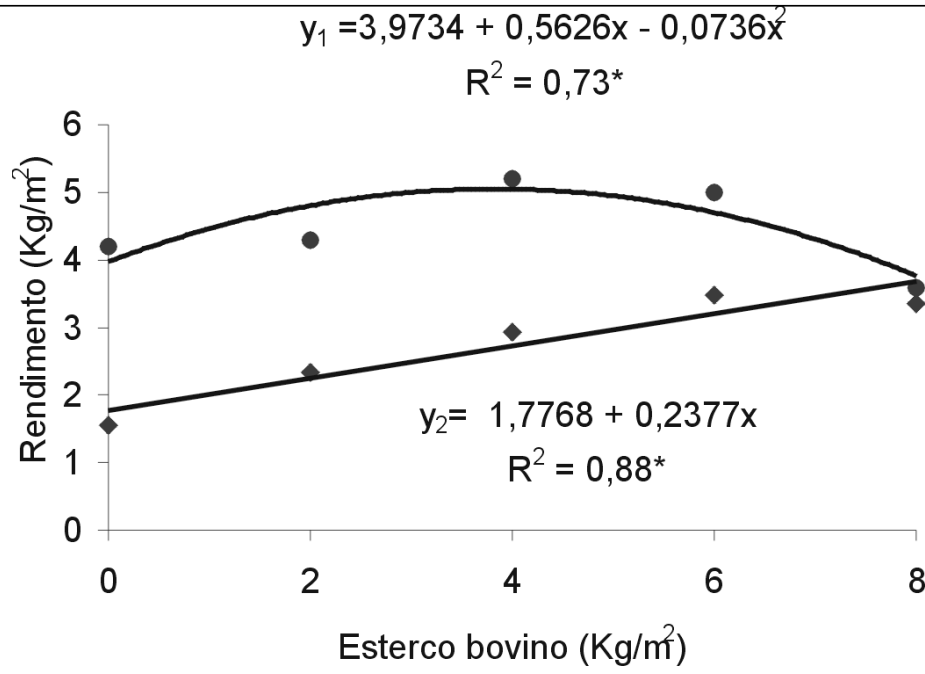

Figura 3. Rendimento de massa verde no coentro, cultivar Verdão, em função de doses de esterco bovino na presença $\left(\mathrm{Y}_{1}\right)$ e ausência $\left(\mathrm{Y}_{2}\right)$ de adubo mineral. Areia, UFPB, 2001.

dose acima de $3,9 \mathrm{~kg} / \mathrm{m}^{2}$. O equilíbrio entre nutrientes proporciona maior rendimentos do que maiores quantidades de macronutrientes, isoladamente (Primavesi, 1985). A estabilização e queda no número de molhos e no rendimento de massa verde nas doses mais elevadas de esterco bovino, na presença de adubo mineral, podem ser devidas ao excesso de nutrientes fornecidos à cultura (Malavolta, 1989; Smith \& Hadley, 1989), ocasionado pela sua concentração no esterco além da quantidade adicionada ao solo. Por outro lado, o aumento no número de molhos e o rendimento de massa verde verificados com a elevação das doses de esterco bovino na ausência do adubo mineral, podem ser atribuídos ao fato de que quantidades adequadas de esterco de boa qualidade são capazes de suprir as necessi-
HORTIVALE. Sementes de coentro Verdão: informativo ao agricultor. 2 p, 1987 (Boletim informativo). KIMOTO, T. Nutrição e Adubação de repolho, couve-flor e brocoli. In: NUTRIÇÃO E ADUBAÇÃO DE HORTALIÇAS. Jaboticabal, 1993. Anais... Jaboticabal, UNESP. 1993. p. 149-178. MACHADO, M.O.; GOMES, A.S.; TURATTI, E.A.P.; SILVEIRA JUNIOR, P. Efeito da adubação orgânica e mineral na produção do arroz irrigado e nas propriedades químicas e físicas do solo de Pelotas. Pesquisa Agropecuária Brasileira. Brasília, v. 18, n. 6, p. 583-591, 1983.

MALAVOLTA, E. $A B C$ da adubação. 5. ed. São Paulo: Agronômica Ceres, 1989. 292 p. OLIVEIRA, A.P.; FERREIRA, D.S.; COSTA, C.C.; SILVA, A.F.; ALVES, E.U. Uso de esterco bovino e húmus de minhoca na produção de repolho híbrido. Horticultura Brasileira, Brasília, v. 19, n. 1, p. 70 - 73, 2001.

OLIVEIRA, A.P.; FREITAS NETO, P.A.; SANTOS, E.S. Produtividade do inhame em função de fertilização orgânica e mineral e de épocas de colheita. Horticultura Brasileira, Brasília, v. 19, n. 2, p. $144-147,2001$ a.

OLIVEIRA, A.P.; SILVA, J.A.; ALVES, E.U.; NORONHA, M.A.S.; CASSIMIRO, C.M. MENDONÇA, F.G. Rendimento de feijão-caupi cultivado com esterco bovino e adubo mineral. Horticultura Brasileira, Brasília, v. 19, n. 1, p. 81 - 84, 2001 b. PEDROSA, F.S.; NEGREIROS, M.Z.; NOGUEIRA, I.C.C. Aspectos da cultura do coentro. Informe Agropecuário, Belo Horizonte, v. 10, n. 120, p. 75-78, 1984.

PIMENTEL, A.A.M.P. Olericultura no trópico úmido: hortaliças na Amazônia. São Paulo, Agronômica Ceres, 1985, 322 p.

PRIMAVESI, A. Manejo ecológico do solo: a agricultura em regiões tropicais. São Paulo, editora Nobel, 1985, $541 \mathrm{p}$.

SAEG - Sistema para análise estatística, versão 8.0. Viçosa-MG: Fundação Artur Bernardes, 2000 SANTOS, G.M.; OLIVEIRA, A.P.; SILVA, J.A.L.; ALVES, E.U.; COSTA, C.C.; Características e rendimento de vagem do feijão-vagem em função de fontes e doses de matéria orgânica. Horticultura Brasileira, Brasília, v. 19, n. 1, p. 30-35, 2001.

SHARMA, R.N.; ISRAEL, S. Effect of date of sowing and level of nitrogen and phosphurus on growth and seed yield of coriander (Coriandrum sativum L.). Indian Journal of Agronomy. v. 36, n. 2, p. $180-184,1991$.

SILVA JUNIOR, A.A. Adubação mineral e orgânica em repolho (Brassica oleracea L. var. capitata L.). I. Produção total e comercial. Horticultura Brasileira, v.2, n.1, p.13-16, 1984.

SINGH, S.D.; RAO, J.S. Yield-water-nitrogen response analysis in coriander. ANNALS OF ARID ZONE. v. 33, n. 3, p. $239-243,1994$.

SMITH, S.R.; HADLEY, P.A. Comparison of organic and inorganic nitrogen fertilizers their nitrate- $\mathrm{N}$ and ammonium- $\mathrm{N}$ release characteristics and effects on the growth response of lettuce (Lactuca sativa L. cv. Fortune). Plant and Soil, v. 115, n. 1, p. 135-144, 1989.

TOMAR, S.S.; GUPTA, K.P.; ABBAS, M.; NIGAM, K.B. Effect of irrigation and fertility levels on growth and yield of coriander (Coriandrum sativum). Indian Journal of Agronomy. v. 39, n.3, p. 442-447, 1994.

FILGUEIRA, F.A.R. $A B C$ da Olericultura: guia da pequena horta. São Paulo: Agronômica Ceres, 1987, $164 \mathrm{p}$.

FILGUEIRA, F.A.R. Novo Manual de Olericultura: Agrotecnologia moderna na produção e comercialização de hortaliças. Viçosa, 2000, 402 p.
VIDIGAL, S.M.; SEDIYAMA, M.A.N.; GARCIA, N.C.P.; MATOS, A.T.. Produção de alface cultivada com diferentes compostos orgânicos e dejetos suínos. Horticultura Brasileira, Brasília, v. 15, n. 1,1997. 